\title{
Electrical and Interfacial Properties of $p$-Si/P3HT Organic-on-Inorganic Junction Barrier
}

\author{
F. Yakuphanoglu ${ }^{a, *}$, M. Shah ${ }^{b}$ And W. Aslam Farooq ${ }^{c}$ \\ ${ }^{a}$ Physics Department, Faculty of Science, Firat University, Elazig, Turkey \\ ${ }^{b}$ GIK Institute of Engineering Science and Technology, Topi, Swabi, Khyber Pakhtunkhwa, 23640, Pakistan \\ ${ }^{c}$ Department of Physics and Astronomy, College of Science, King Saud University \\ Riyadh, Kingdom of Saudi Arabia
}

(Received February 22, 2011; in final form March 15, 2011)

\begin{abstract}
The electrical characterization of the $\mathrm{Al} / p$-Si/P3HT/Ag organic-on-inorganic diode was done by currentvoltage, capacitance-voltage and conductance-voltage methods. The values of ideality factor and barrier height of the diode were determined from the current-voltage characteristics and found as 2.32 and $0.77 \mathrm{eV}$, respectively. These values were also determined from Cheung's functions and Norde's method due to the non-ideal behavior of the diode. The electronic parameters obtained from the various methods indicate a good consistency with each other. The density of interface states for $\mathrm{Al} / p$-Si/P3HT/Ag organic-on-inorganic diode was found to be $7.64 \times 10^{10} \mathrm{~cm}^{-2} \mathrm{eV}^{-1}$. The obtained electrical parameters of the $\mathrm{Al} / p$-Si/P3HT/Ag organic-on-inorganic diode are higher than that of the conventional $\mathrm{Ag} / p$-Si Schottky diodes. This indicates that the electrical properties of the silicon Schottky diodes can be controlled using organic interfacial layer.
\end{abstract}

PACS: 81.07.Pr, 78.40.Me

\section{Introduction}

The properties of metal/semiconductor (MS) contacts or organic/inorganic semiconductor structures are of great importance for the potential use in electronic and optoelectronic devices [1-4]. Heterojunctions and the Schottky diodes have been studied by many researchers using different organic semiconducting materials [5-8]. Organic semiconductor devices have attracted great attention due to its advantages over inorganic semiconductor which include large variety of molecular and crystal structure, low material cost, flexibility, low-temperature processing and large area device processing. Therefore, considerable interest of the researchers has been increased in the fabrication of organic devices by employing various organic materials as active layer [9-14]. Among organic materials, polymers have mechanical flexibility, and their thin films can be deposited by spin-casting, drop-casting, dip-coating and printing. In recent years, conducting polymers become very attractive for various electronic devices [15-24]. In particular, the easy processability and higher field effect mobility of poly(3-hexylthiophene) (P3HT) make it very promising candidate for the development of future organic electronic devices $[25,26]$ and organic-silicon heterostructure diode can be fabricated using P3HT organic semiconductor. Thus, our aim is to investigate the electrical properties of $p$-Si $/ \mathrm{Ag}$ diode by the insertion of P3HT organic layer between $p$-Si semiconductor using forward bias $I-V$ characteristics and

* corresponding author; e-mail: fyhanoglu@firat.edu.tr impedance spectroscopy measurements and is to compare the parameters of the $\mathrm{Al} / p-\mathrm{Si} / \mathrm{P} 3 \mathrm{HT} / \mathrm{Ag}$ organic-on-inorganic diode with those of conventional metal/ semiconductor diodes.

In present paper, we present the preparation and characterization of the $\mathrm{Al} / p-\mathrm{Si} / \mathrm{P} 3 \mathrm{HT} / \mathrm{Ag}$ organic-on-inorganic diode.

\section{Experimental details}

A $p$-Si wafer with (100) orientation was used as an inorganic semiconductor. The Si-wafer was chemically cleaned using the RCA cleaning procedure [i.e. a $10 \mathrm{~min}$ boil in $\mathrm{NH}_{4} \mathrm{OH}+\mathrm{H}_{2} \mathrm{O}_{2}+6 \mathrm{H}_{2} \mathrm{O}$ followed by a $10 \mathrm{~min}$ boil in $\mathrm{HCl}+\mathrm{H}_{2} \mathrm{O}_{2}+6 \mathrm{H}_{2} \mathrm{O}$. The native oxide on the front surface of the silicon was removed in $\mathrm{HF}: \mathrm{H}_{2} \mathrm{O}$ (1:10) solution and finally the wafer was rinsed in deionised water for $30 \mathrm{~s}$. The ohmic contact was done by evaporating $\mathrm{Al}$ on the back of the $p$-Si substrate at $10^{-5}$ Torr and it was treated at $570^{\circ} \mathrm{C}$ for $5 \mathrm{~min}$ in $\mathrm{N}_{2}$ atmosphere. The solution of $\mathrm{P} 3 \mathrm{HT}$ was prepared in chlorobenzene and the film was coated onto $p$-type silicon substrate using a spin coater at $1000 \mathrm{rpm}$ and then, the film was dried at room temperature. The thickness of P3HT layer was determined to be about $100 \mathrm{~nm}$ by atomic force microscopy (AFM). Ag metal was formed on P3HT film through a shadow mask in the vacuum system of $10^{-5}$ Torr. In this way, an $\mathrm{Al} / p-\mathrm{Si} / \mathrm{P} 3 \mathrm{HT} / \mathrm{Ag}$ organic-on-inorganic diode was fabricated. The area of circular diode contact was $3.14 \times 10^{-2} \mathrm{~cm}^{2}$. The $I-V$ and $C-V-f$ measurements of the device were performed using a Keithley $4200 \mathrm{AFM}$ Semiconductor characterization system. The structural 
properties of the organic material deposited on $p$-type silicon were analyzed by a Park System XE 100E AFM.

\section{Results and discussion}

The morphology properties of the P3HT film deposited on $p$-Si substrate were investigated by AFM. The AFM image of the film is shown in Fig. 1. As seen in Fig. 1, the P3HT film is formed from microparticles. The surface roughness of the film was found to be $53.25 \mathrm{~nm}$.

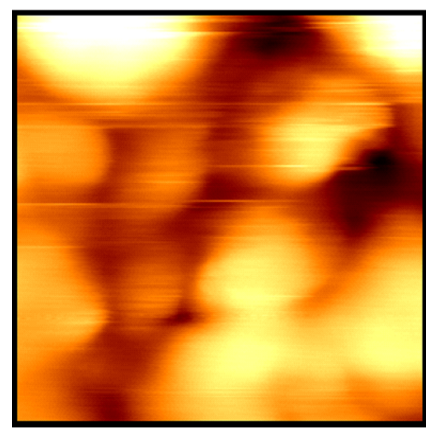

Fig. 1. AFM image of the P3HT thin film on $p$-Si.

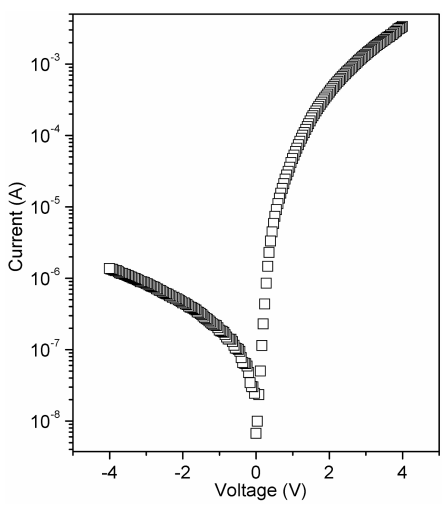

Fig. 2. Current-voltage characteristics of the $\mathrm{Al} / p$-Si/ $\mathrm{P} 3 \mathrm{HT} / \mathrm{Ag}$ diode.

Figure 2 shows the current-voltage $(I-V)$ characteristics of the $\mathrm{Al} / p$-Si/P3HT/Ag organic-on-inorganic diode. As seen in Fig. 2, the diode exhibits a rectification behavior with a non-linear behavior. This behavior can result from series resistance and interface states, because the lower the interface density and the series resistance, the greater is the range over which $\ln I-V$ does in fact yield a straight line [27]. The rectification ratio (RR) which is the ratio of forward to reverse bias current at the same voltage was found to be $2.47 \times 10^{3}$ at $\pm 4 \mathrm{~V}$. The $I-V$ characteristics of the organic and organic-on-inorganic structures can be analyzed by the following relation [9-14]:

$$
I=I_{0} \exp \left(-\frac{q\left(V-I R_{\mathrm{s}}\right.}{n k T}\right),
$$

where $I_{0}$ is the saturation current given by

$$
I_{0}=A A^{*} T^{2} \exp \left(-\frac{q \phi_{\mathrm{b}}}{k T}\right),
$$

where $A$ is the contact area, $A^{*}$ is the Richardson constant, $T$ is the temperature in $[\mathrm{K}], \phi_{\mathrm{b}}$ is the barrier height, $k$ is the Boltzmann constant, $R_{\mathrm{s}}$ is the series resistance and $n$ is the ideality factor. The ideality factor $n$ can be determined from the slope of the linear region of the forward bias $\ln I-V$ curve by using the relation [28]:

$$
n=\frac{q}{K T} \frac{\mathrm{d} V}{\mathrm{~d}(\ln I)} .
$$

The value of ideality factor was found 2.32 by using Eq. (3) and the obtained $n$ value is higher than that of $\mathrm{Ag} / p$-Si diode. The obtained $n$ value is higher than unity. This is attributed to the high value of series resistance $\left(R_{\mathrm{S}}\right)$ and interface states [29]. The presence of an oxide film plus the organic P3HT layer at $\mathrm{Ag} / p$-Si interface causes a non-ideal behavior by changing the positions of energy level in metal/semiconductor interface. The value of barrier height was calculated using Eq. (2) and was found to be $0.77 \mathrm{eV}$. The obtained $\phi$ value of the organic-on-inorganic diode is higher than that of $\mathrm{Ag} / p$-Si Schottky diodes [30]. The increase in barrier height of the diode can result from the interface properties of metal/semiconductor interfaces passivated by P3HT organic layer surface. When $\mathrm{Si}$ and organic semiconductor interacted, the lowest unoccupied molecular orbital (LUMO) and highest occupied molecular orbital (HOMO) levels of the organic semiconductor and work function of the metal is realigned and in turn, the electron affinity of the semiconductor at the organic/inorganic semiconductor interface is changed and this can cause a increase in the barrier height.

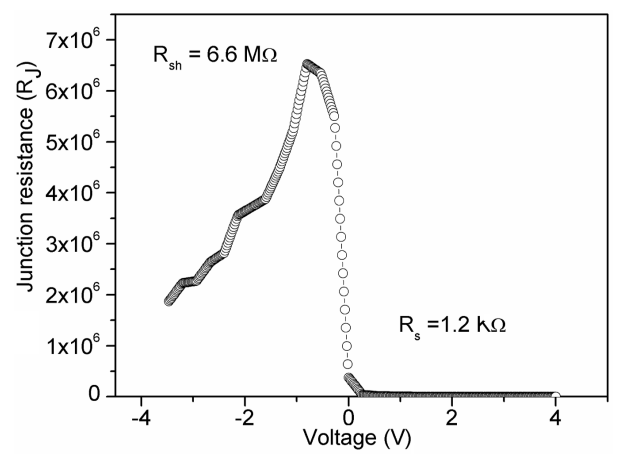

Fig. 3. Plot of $R_{j}$ vs. $V$ for the $\mathrm{Al} / p-\mathrm{Si} / \mathrm{P} 3 \mathrm{HT} / \mathrm{Ag}$ diode.

Figure 3 shows the plot of the $R_{j}$ vs. $V$ of the $\mathrm{Al} / p$-Si/ $\mathrm{P} 3 \mathrm{HT} / \mathrm{Ag}$ organic-on-inorganic diode. The $R_{j}$ values were obtained taking derivative of Fig. 2. It is well known that at sufficient higher voltages, the junction resistance approaches to a minimum value of resistance known as 


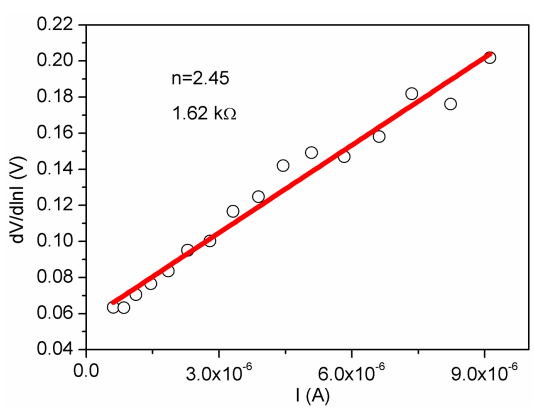

Fig. 4. Plot of $\mathrm{d} V / \mathrm{d} \ln I$ vs. $I$ for the $\mathrm{Al} / p$-Si $\mathrm{P} 3 \mathrm{HT} / \mathrm{Ag}$ diode.

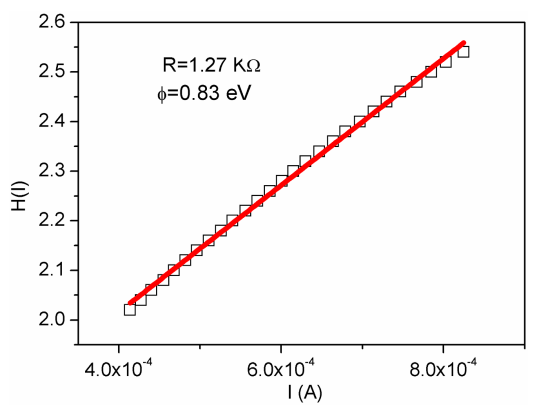

Fig. 5. Plot of $H(I)$ vs. $I$ for the $\mathrm{Al} / p-\mathrm{Si} / \mathrm{P} 3 \mathrm{HT} / \mathrm{Ag}$ diode.

series resistance $\left(R_{\mathrm{s}}\right)$, while in reverse bias, the maximum value of the resistance is called shunt resistance $\left(R_{\mathrm{sh}}\right)$. The values of series and shunt resistance for the diode were found to be $1.2 \mathrm{k} \Omega$ and $6.6 \mathrm{M} \Omega$, respectively. The $R_{\mathrm{s}}$ value of the $\mathrm{Al} / p$-Si/P3HT/Ag the organic-on-inorganic diode is higher than that of $\mathrm{Ag} / p$-Si Schottky diode [30] and it causes to be non-ideal behavior of the diode. Thus, the electrical parameters of the non-ideal diode can be obtained by the method proposed by Cheung and Cheung [31, 32]. In this method, the barrier height $(\phi)$, ideality factor $(n)$ and series resistance $\left(R_{\mathrm{S}}\right)$ values of organic-on-inorganic diodes $[5,10-14]$ can be determined by the following relations:

$$
\begin{aligned}
& \frac{\mathrm{d} V}{\mathrm{~d} \ln (I)}=n \frac{k T}{q}+I R_{\mathrm{s}}, \\
& H(I)=V-n \frac{k T}{q} \ln \left(\frac{I}{A A^{*} T^{2}}\right)
\end{aligned}
$$

and

$$
H(I)=I R_{\mathrm{s}}+n \phi .
$$

The plot of $(\mathrm{d} V / \mathrm{d} \ln I)$ vs. $I$ is shown in Fig. 4. The slope of the linear portion of the $\mathrm{d} V / \mathrm{d}(\ln I)-I$ plot gives the series resistance, while its intercept with the $y$-axis gives the ideality factor. The ideality factor and series resistance values of the diode were calculated from Fig. 4 and found to be 2.45 and $1.62 \mathrm{k} \Omega$, respectively. The relation between $H(I)$ and $I$ is also plotted for the $\mathrm{Al} / p-\mathrm{Si}$ / $\mathrm{P} 3 \mathrm{HT} / \mathrm{Ag}$ organic-on-inorganic diode (Fig. 5). The $\phi$ and $R_{\mathrm{S}}$ values for the diode were calculated from the $H(I)-I$ plot and found to be $0.83 \mathrm{eV}$ and $1.57 \mathrm{k} \Omega$, respectively. The value of series resistance obtained by applying Cheung's functions shows a good consistency with each other. The junction parameters of organic-on-inorganic diodes were also extracted by using another method proposed by Norde [33-36]. The Norde function is given as

$$
F(V)=\frac{V}{\gamma}-\frac{k T}{q} \ln \left(\frac{I}{A A^{*} T^{2}}\right) .
$$

The effective barrier height is given by the following relation:

$$
\phi_{\mathrm{b}}=F\left(V_{0}\right)+\frac{V_{0}}{\gamma}-\frac{k T}{q}
$$

and

$$
R_{\mathrm{s}}=\frac{k T(\gamma-n)}{q I_{0}}
$$

where $\gamma$ is a dimensionless integer greater than ideality factor and $F\left(V_{0}\right)$ is the minimum value of $F(V)$. The plot of $F(V)$ versus $V$ for the $\mathrm{Al} / p$-Si/P3HT $/ \mathrm{Ag}$ organic-on-inorganic diode is shown in Fig. 6. With help of this plot, the $\phi$ and $R_{\mathrm{s}}$ values were calculated to be $0.94 \mathrm{eV}$ and $1.76 \mathrm{k} \Omega$, respectively. The obtained $R_{\mathrm{s}}$ value is quite high due to the organic P3HT layer. This suggests that the P3HT organic layer increases both ideality factor and series resistance as well as barrier height.

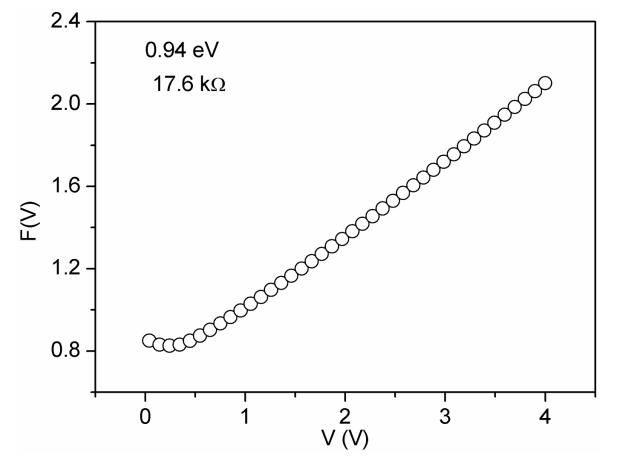

Fig. 6. Plot of $F(V)$ vs. $V$ of the $\mathrm{Al} / p-\mathrm{Si} / \mathrm{P} 3 \mathrm{HT} / \mathrm{Ag}$

fliode order to analyze the effects of higher bias voltages, the current-voltage characteristics were plotted on double logarithmic scale, as shown in Fig. 7. As seen in Fig. 7, the higher voltages make a contribution to current voltage characteristics of the diode. The curve of the diode exhibits two distinct regions attributed to different conduction mechanisms. This plot was analyzed using a power law of the form $I \propto V^{m}$; here $m$ is constant describing the charge transport mechanism. The $m$ values were found 3.6 and 3.03, respectively. These values indicate a trap charge limiting current and trap filled limiting charge current regions. The trap charge limited current (TCLC) conduction becomes important when the density of injected free-charge carriers into the highly resistive organic material is much larger than the thermally-generated free-charge-carriers in the layer to 


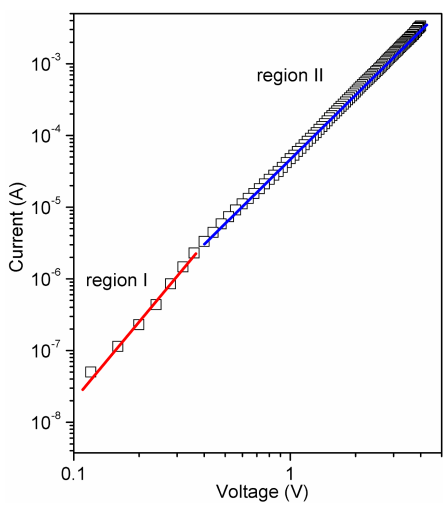

Fig. 7. $I-V$ characteristics of the $\mathrm{Al} / p-\mathrm{Si} / \mathrm{P} 3 \mathrm{HT} / \mathrm{Ag}$ diode in double logarithmic scale.

sustain flow of the TCLC. The slope of region I is about 3.6, indicating that the forward biased current is TCLC controlled by exponential distribution of trap levels [9]. The region II with slope $\approx 3$ indicates that at higher voltages the traps in the device approach the "trap-filled" limit $[2,37]$. In this region, the increase rate of current with voltage decreases. This suggests that most of traps are filled and contribution of free carrier to electric field becomes appreciable [38].

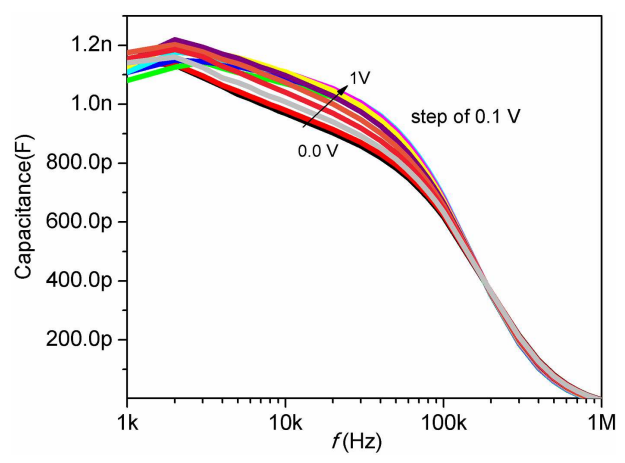

Fig. 8. Capacitance-frequency characteristics of the $\mathrm{Al} / p$-Si/P3HT $/ \mathrm{Ag}$ diode at different bias voltages.

Another parameter affecting the non-ideal behavior is interface charge. Thus, we have to determine interface state density of the diode. For the determination of interface state density, there are more techniques and one of them is conductance technique. This technique determines the interface state density throughout the depletion region by point to point [39]. It has been reported that the results obtained by conductance technique are more accurate and reliable than capacitance technique [40], because the conductance only comes from the interface states [39]. The conductance losses are the base of conductance technique resulting from the exchange of majority carriers between the interface states and majority carrier band of the semiconductor when a small alternating current (AC) signal is applied to the

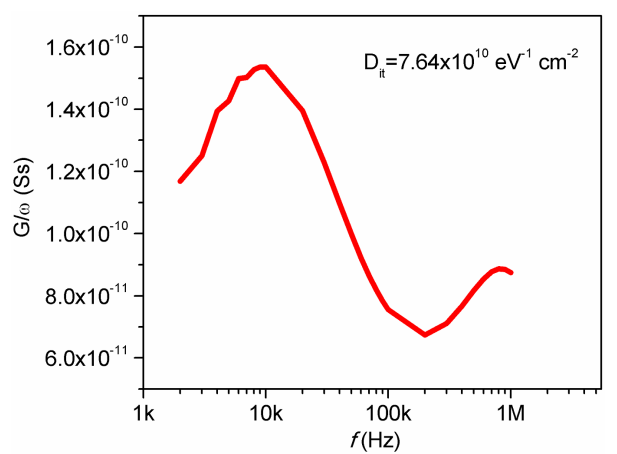

Fig. 9. Plot of $G / \omega$ vs. $f$ plot of the $\mathrm{Al} / p-\mathrm{Si} / \mathrm{P} 3 \mathrm{HT} / \mathrm{Ag}$ diode.

semiconductor devices [28, 41]. The Fermi level will start to oscillate about the mean position when a small $\mathrm{AC}$ signal is superimposed on a direct current (DC) bias. Therefore, it is concluded that there may be a capacitance due to interface states in excess to depletion layer capacitance, which depends upon the relaxation time of the interface states and the frequency of the AC signal. The capacitance-frequency characteristics of the diode are shown in Fig. 8 at various bias voltages $(0.0 \mathrm{~V}$ to $1 \mathrm{~V}$ with a step of $0.1 \mathrm{~V})$. The capacitance increases with decrease in frequency. This behavior is attributed to the interface states. It is well known that the interface states at lower frequencies follow the $\mathrm{AC}$ signal, while at higher frequencies thus the interface states cannot follow the AC signal. Therefore the contribution of the interface state capacitance do not appreciably change the total capacitance [42]. The higher values of capacitance at low frequency are due to the excess capacitance resulting from the interface states in equilibrium with the $p$-Si that can follow the AC signal. The density of interface states can be determined from $G-f$ measurements proposed by conductance method described by Nicollian and Brews [41]. In this method, parallel capacitance $C_{\mathrm{p}}$ and conductance $G_{\mathrm{p}}$ equations are represented by the following relation [41]:

$$
G_{\mathrm{p}}=\frac{C_{\mathrm{it}}}{2 \tau} \ln \left(1+\omega^{2} \tau^{2}\right)
$$

and

$$
C_{\mathrm{p}}=C_{\mathrm{d}}+\frac{C_{\mathrm{it}}}{\omega \tau} \arctan (\omega \tau),
$$

where $C_{\mathrm{it}}=q A D_{\mathrm{it}}$ is the interface state capacitance and $A$ is the diode constant area, $\omega$ is the angular frequency, $\tau$ is the time constant of the interface state. The interface state density of the diode can be determined from the $(G / \omega)-f$ plot (Fig. 9). The interface state density of the diode was found to be $7.64 \times 10^{10} \mathrm{eV}^{-1} \mathrm{~cm}^{-2}$. The obtained $D_{\text {it }}$ value of the diode is higher than that of the diodes like $p$-Si/C60:MEH-PPV diode [13], $\mathrm{Sn} /$ pyronine-B $/ p$-Si structures $[43,25]$. This suggests that the interface states properties of the conventional Si Schottky diodes can be controlled using various organic layers. 


\section{Conclusions}

The electronics and interface parameters of the $\mathrm{Al} / p$-Si/P3HT/Ag organic-on-inorganic diode have been extracted. The electrical parameters like ideality factor, barrier height, interface state density and series resistance of the diode were determined. The obtained parameters are higher than that of conventional $\mathrm{Ag} / p-\mathrm{Si}$ Schottky diodes. This indicates that the electrical properties of the conventional Si Schottky diodes can be controlled by organic semiconductors rather than fabrication of novel conventional Schottky diodes.

\section{Acknowledgments}

This work was supported by Feyzi AKKAYA Scientific Activates Supporting Fund (FABED) and King Saud University under a grant number: KSU-VPP-102 and Author wishes to thank KSU and FABED for young scientist grant.

\section{References}

[1] T. Maeda, S. Takagi, T. Ohnishi, M. Lippmaa, Mater. Sci. Semicond. Process 9, 706 (2006).

[2] S. Aydogan, K. Çinar, H. Asil, C. Coskun, A. Türüt, J. Alloys Comp. 476, 913 (2009).

[3] M. Shah, M.H. Sayyad, Kh.S. Karimov, M.M. Tahir, Optoel. Adv. Mater.-Rapid Comm. OAM-RC 3,831 (2009).

[4] M. Shah, M.H. Sayyad, Kh.S. Karimov, M.M. Tahir, Physica B 405, 1188 (2010).

[5] S. Aydogan, Ü. Incekara, A.R. Deniz, A. Türüt, $M i$ croelectron. Eng. 87, 2525 (2010).

[6] J.S. Park, B.R. Lee, J.M. Lee, J.S. Kim, S.O. Kim, M.H. Song, Appl. Phys. Lett. 96, 243306 (2010).

[7] Ö. Güllü, S. Asubay, M. Biber, T. Kiliçoglu, A. Türüt, Eur. Phys. J. Appl. Phys. 50, 10401 (2010).

[8] F. Yakuphanoglu, Synth. Met. 158, 108 (2008).

[9] M. Shah, Kh.S. Karimov, Z. Ahmad, M.H. Sayyad, Chin. Phys. Lett. 27, 106102 (2010).

[10] S. Okur, F. Yakuphanoglu, M. Ozsoz, P. Kara Kadayifcilar, Microelectron. Eng. 86, 2305 (2009).

[11] M. Shah, M.H. Sayyad, Kh.S. Karimov, F. Wahab, J. Phys. D, Appl. Phys. 43, 405104 (2010).

[12] F. Yakuphanoglu, Synth. Met. 160, 1551 (2010).

[13] F. Yakuphanoglu, Sen. Actuat. A 141, 383 (2008).

[14] F. Yakuphanoglu, Sen. Actuat. A 153, 191 (2009).

[15] A.R. Brown, C.P. Jarrett, D.M. de Leeuw, M. Matters, Synth. Met. 88, 37 (1997).

[16] G. Horowitz, Adv. Mater. 10, 635 (1998).

[17] M. Helgesen, R. Sondergaard, F.C. Krebs, J. Mater. Chem. 20, 36 (2010).

[18] Y. Gofer, H. Sarker, J.G. Killian, T.O. Poehler, P.C. Searson, Appl. Phys. Lett. 71, 1582 (1997).
[19] H. Kaden, H. Jahn, M. Berthold, K. Juttner, K.M. Mangold, S. Schafer, Chem. Eng. Technol. 24, 1120 (2001).

[20] Y. Wang, X. Jing, Polym. Adv. Technol. 16, 344 (2005).

[21] W.H. Kim, G.P. Kushto, H. Kim, Z.H. Katafi, J. Appl. Polym. Sci.: Part B: Polym. Phys. 41, 2522 (2003).

[22] J. Ouyang, C.W. Chu, C.R. Szmanda, L. Ma, Y. Yang, Nat. Mater. 3, 918 (2004).

[23] P. Kumar, S.C. Jain, A. Misra, M.N. Kamalasanan, V. Kumar, J. Appl. Phys. 100, 114506 (2006).

[24] J. Nayak, S.K. Mahadeva, Y. Chen, K.S. Kang, J. Kim, Thin Solid Films 518, 5626 (2010).

[25] H. Sirringhaus, P.J. Brown, R.H. Friend, M.M. Nielsen, K. Bechgaard, B.M.W. Langeveld-Voss, A.J.H. Spiering, R.A.J. Janssen, E.W. Meijer, P. Herwig, D.M. de Leeuw, Nature 401, 1038 (1999).

[26] E.J. Meijer, A.V.G. Mangnus, C.M. Hart, D.M. de Leeuw, T.M. Klapwijk, Appl. Phys. Lett. 78, 3902 (2001).

[27] M. Çakar, Y. Onganer, A. Türüt, Synth. Met. 126, 213 (2002).

[28] E.H. Rhoderick, R.H. Williams, MetalSemiconductor Contact, Clarendon Press, Oxford 1988.

[29] E.H. Rhoderick, Metal-Semiconductor Contacts, Oxford University Press, Oxford 1978.

[30] B. Cvikl, D. Koršak, Zs.J. Horváth, Vacuum 50, 385 (1998).

[31] S.K. Cheung, N.W. Cheung, Appl. Phys. Lett. 49, 85 (1986).

[32] L. Paoli, P.A. Barnes, Appl. Phys. Lett. 28, 714 (1976).

[33] H. Norde, J. Appl. Phys. 50, 5052 (1979).

[34] A.A.M. Farag, B. Gunduz, F. Yakuphanoglu, W.A. Farooq, Synth. Met. 160, 2559 (2010).

[35] Y.S. Ocak, M. Kulakci, T. Kılıcoğlu, R. Turan, K. Akkılıc, Synth. Met. 159, 1603 (2009).

[36] Ş. Aydoğan, M. Sağlam, A. Türüt, Microelectron. Eng. 85, 278 (2008).

[37] S.R. Forrest, Chem. Rev. 97, 1793 (1997).

[38] D.L. Lile, in: Physics and Chemistry of III-V Compound Semiconductor Interfaces, Ed. C.W. Wilmsen, Plenum Press, New York 1985.

[39] S. Logothetidis, J. Appl. Phys. 82, 5017 (1997).

[40] E.H. Nicollian, A. Goetzberger, Appl. Phys. Lett. 7, 216 (1965).

[41] E.H. Nicollian, J.R. Brews, MOS Physics and Technology, Wiley, New York 1982.

[42] M.E. Aydin, F. Yakuphanoglu, Microelectron. Eng. 85, 1836 (2008).

[43] M. Çakar, A. Türüt, Synth. Met. 138, 549 (2003). 